\title{
ACOUSTIC SIMULATION OF THE CENTRAL HALL IN PALAU GÜELL BY GAUDÍ
}

\author{
Genaro González, Albert Samper, Blas Herrera* \\ Universitat Rovira i Virgili \\ Spain
}

*Corresponding author: blas.herrera@urv.cat

\begin{abstract}
Introduction: Quadric surfaces are commonly used in buildings due to their geometric ability to distribute and focus sound waves. The Central Hall in Palau Güell - a UNESCO World Heritage Site — is topped by an ellipsoidal dome. Antoni Gaudí envisaged this room as a concert hall where the organ and the dome play a lead role. Methods: The two previously mentioned elements are the main subject of our paper, which serves two purposes: 1) determining the values of the acoustic parameters of the hall through onsite measurement and also through simulation, and 2) using the geometric parameters of the quadric surface, which best fits the dome, in order to check whether it is possible to improve the acoustics of the hall by placing a new emission source at the focus of the dome's ellipsoid. Results and Discussion: Contrary to the authors' expectations, due to the focal reflection properties of the quadric surface, some acoustic parameters on the listening plane do not improve significantly. Therefore, we conclude that Gaudí took the acoustical impact into account when designing this hall.
\end{abstract}

\section{Keywords}

Ellipsoidal dome, acoustics, Palau Güell, Antoni Gaudí.

\section{Introduction}

The Palau Güell (1885-1890) is amongst the first important projects by Antoni Gaudí (1852-1926), and the only new construction he was able to finish. The building was commissioned by the Barcelona businessman Eusebi Güell Bacigalupi, who gave the architect total freedom in design (González et al., 2013).

One of the most representative spaces in Palau Güell is the Central Hall (Fig. 1). Apart from being the space around which the entire residence was arranged, it was created and designed to hold music recitals. Being a music lover, Eusebi Güell suggested that Gaudi's project should include a room where he could listen to live music in the company of friends and artists of their time. As a matter of fact, several Wagner operas were presented in Barcelona during the construction of Palau Güell, resulting in a Wagnerian craze in which Eusebi Güell took an active part (Granell, 2002; Lahuerta, 1992). This stirred up his interest in incorporating music into the palace's design. In addition to using the Central Hall for music recitals - even with choirs and an organ its design was also suitable for religious services, conferences, and public lectures.

According to González et al. (2013), the decision to provide the palace with an organ was taken very early and had a direct impact on the geometric design of the hall. More specifically, the Central Hall is topped by an ellipsoidal dome with many small holes and a central eye, which ensure daylighting.
The dome spans above a quadrangular area of approximately $60 \mathrm{~m}^{2}$. The height to the central eye is $16.17 \mathrm{~m}$. Throughout this height, the Central Hall musically and visually links three levels: a first level where the audience seats were arranged, a second level for the orchestra, and a third level for the choral ensembles. The organ pipes were installed between the third level and the dome. This hall has an approximate volume of $996.40 \mathrm{~m}^{3}$ and it features ceramic tilings, marble ornaments, glass enclosures, and oak wood flooring. Therefore, a priori, it is a very reverberant space (Figs. 1 and 2).

Antoni Gaudí envisaged this room as a concert hall where the organ and the dome play a lead role. These two elements are directly involved in our calculations. The following are the topics covered in our paper:

a) Despite the interior finishes and the proportions of space, it is commonly claimed that the Central Hall in Palau Güell has good acoustics. Nonetheless, we are not aware of any rigorous study, which quantifies the acoustic quality at the listening plane, where the audience sat. This paper provides a measure of the acoustic parameters.

b) We are not aware of any original documents by Gaudí explaining the reasons why he designed an ellipsoidal dome. Quadric surfaces are commonly used in theaters, stadiums, and public venues due to their geometric ability to distribute and focus sound (Kircheri, 1673; León-Rodríguez, 1998). Based on 

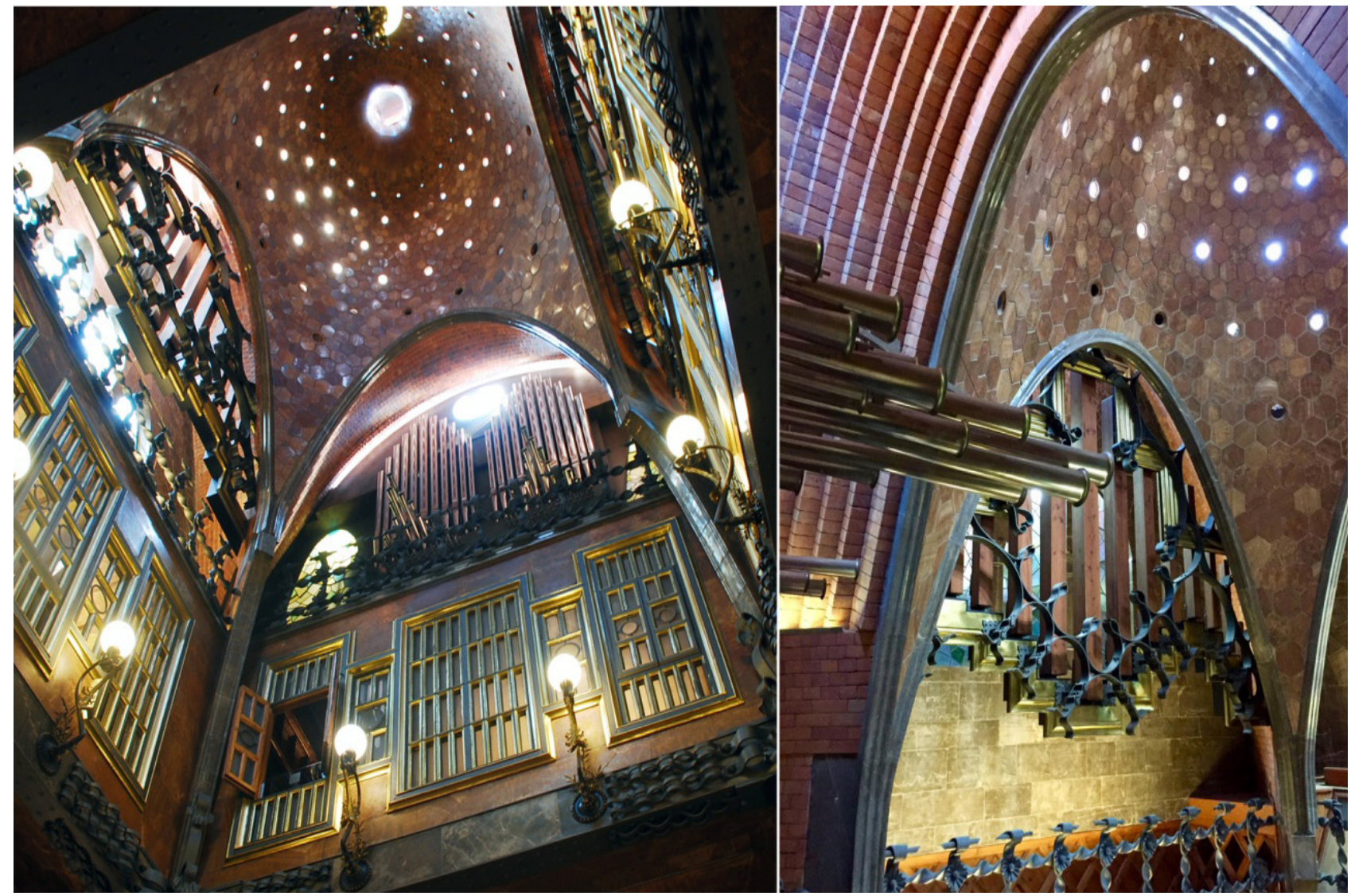

Figure 1. Images of the Central Hall in Palau Güell, showing the two main elements considered in this paper: the ellipsoidal dome and the organ (photos taken by the authors)

the architectural application of these geometric and acoustics properties throughout history, it is important to note that Gaudí designed an ellipsoidal surface in order to adequately distribute the organ sound throughout the entire room. In this paper, we determine the acoustic impact of the dome's surface on the listening plane (where the audience sat).

c) In addition to the foregoing, we analyzed the geometric parameters of the quadric surface, which best fits the dome, and placed the emission source in different positions, but - contrary to our expectations - we did not succeed in significantly improving some of the acoustic parameters at the listening plane. Accordingly, despite the absence of a historical document supplying proof in this regard, we claim that Gaudí took the acoustical impact into account when designing this hall.

In order to investigate these topics, we will generate a virtual simulation of this architectural space. This geometric simulation will enable us to gain a better understanding of the acoustic characteristics and the intelligibility of voice and music in the hall. Our investigation is along the same lines as other research works, such as works on Pompeii's Odeon (Berardi et al., 2016), the Santiago de Compostela Cathedral (Suárez et al., 2015), and the Basilica of San Vitale in Ravenna (Tronchin and Knight, 2016), as well as the Granada Cathedral (Alonso et al., 2017) and the Seville Cathedral
(Alvarez-Morales et al., 2017). Virtual and simulated geometrical acoustics studies by D'Orazio et al. (2016), Segura et al. (2011) and Sender et al. (2018) should also be mentioned.

\section{PRELIMINARY REMARKS}

After defining the study object and the two main elements of the Central Hall, which will be used for this acoustic analysis (the organ as the emission source, and the ellipsoidal dome as the distributing element), we formulate two arrangement cases and generate their respective acoustic simulations, focusing mainly on the music and speech acoustics indicators.

Case 1: For this acoustic simulation of the Central Hall, the emission source is placed at the organ's location (Gaudi's original design), and the sound receivers are evenly distributed across the audience area at a height of $1.20 \mathrm{~m}$ above the floor level (listening plane). Previous to this acoustic simulation, we collected experimental data onsite by placing the emission source at the organ's location and by placing the sound receivers at the same level and the same places as defined for the simulation.

This first case is aimed at 1) confirming or disproving the common claim that the Central Hall of Palau Güell has good acoustics, and 2) providing a measure of the abovementioned acoustic parameters (Fig. 2). 
Case 2: For this acoustic simulation of the Central Hall, the emission source (emitting the same tone as for Case 1) is placed at the upper focal point of the ellipse, resulting from the intersection between a vertical plane and the quadric surface, which best fits the dome, and the sound receivers are evenly distributed across the listening plane as in Case 1 (Fig. 2). The best-fitting quadric surface is an ellipsoid.

The parameters studied, grouped according to the main subjective sensations (Gimenez, 1989, 2001), are:

- Reverberation parameters: T30 and EDT (Reverberation Times), Br (Brilliance).

- $\quad$ Energy parameters: C50 (Clarity for speech) and C80 (Clarity for music), G (Strength).

- Intelligibility parameters: STI.

The main subjective qualities of the concert halls are related to the following parameters:

- Reverberation: It represents the degree of vivacity of the hall.

- Transparency: It is important when hearing music. Transparency refers to the perception of separate tones in time and instruments played simultaneously.

- Intelligibility: this parameter quantifies speech comprehension and is essential for hearing speech.

Furthermore, we took into account the values of Just Noticeable Difference (JND), which is the minimum variation of an acoustic parameter that a person can detect. It is currently considered to be the best indicator with which to assess the subjective perception of variations in acoustical parameters.

\section{Methods}

Experimental data were collected in the empty hall and according to the specifications of ISO 3382-1:2009. These measurements allowed us to calibrate the hall as it is now and they also allowed us to validate the simulated parameter values obtained for Case 1. In order to validate the simulated values, we assigned sound absorption and sound scattering properties to each modeled surface. After validating the simulated parameter values for Case 1 , we compared the two cases stated in this paper. It should be mentioned that the diffraction phenomenon was taken into account. The experimental data were collected using WinMLS2004 software.

The acoustic simulation of the two abovementioned cases was made using CATT Acoustic software (v9.0c). This commercially available software is supported by $3 D$ modeling tools. For the 3D modeling of the hall, we used SketchUp software. Using the generated 3D models, CATT Acoustic simulates sound propagation and provides echograms and synthesized room impulse responses (RIRs). We analyzed the acoustic parameters related to music and speech. Using these tools, we replicated the sound environment of the Central Hall in Palau Güell and obtained simulated acoustic parameter values to be compared with our experimental data. This enabled us to validate these simulated parameter values.

The steps followed:

- Step 1: We collected experimental data onsite at the Central Hall in Palau Güell.

- Step 2: We created a three-dimensional model of the Central Hall. This model is a prerequisite to carry out the simulation.

However, CATT Acoustic can only read 3D polygonal models; it cannot use point clouds or analytical equations. For this reason, we used SketchUp software to model the Central Hall.

Our model consists of two parts: the dome and the rest of the hall. Everything, except for the dome, was modeled on the basis of existing drawings (provided to us by the Diputació de Barcelona) and a whole set of laser measurements and verifications that we carried out onsite.

Before creating a $3 \mathrm{D}$ rendering of the dome, we had to use other techniques, the steps of which are described briefly below:

A) Using photogrammetric techniques and PhotoScan software, we generate a cloud $N=\left\{P_{i}\right\}_{i=1}^{i=n}$ made up by $n=2,145,493$ points forming the dome (Fig. 3).

B) By means of a quadratic surface regression, we obtain the quadratic surface, which best fits the dome. It turns out to be an ellipsoid, so we find its equation and geometric parameters. In order to do that, we use the mathematical procedure outlined hereafter: For the points $P_{i}$, we use 3D coordinates according to the $3 \mathrm{D}$ orthonormal coordinate $\left(x^{\prime}, y^{\prime}, z^{\prime}\right)$ system $\mathcal{R}^{\prime}=\left\{O ; \vec{u}_{1}, \vec{u}_{2}, \vec{u}_{3}\right\}$ of the scanning device. We calculate, which is the regression quadratic surface for , and we obtain its general equation, Eq. (1), in the reference system $R^{\prime}$ :

$$
\begin{aligned}
\Gamma \equiv 0= & B_{0} x^{\prime 2}+C_{0} y^{2}+D_{0} z^{\prime 2}+E_{0} x^{\prime} y^{\prime}+F_{0} x^{\prime} z^{\prime}+ \\
& G_{0} y^{\prime} z^{\prime}+H_{0} x^{\prime}+I_{0} y^{\prime}+J_{0} z^{\prime}+1 .
\end{aligned}
$$

This regression surface $\Gamma$ is the one that best fits the point cloud, minimizing the sum of the quadratic residues $. \sum_{i=1}^{i=n} \varepsilon_{i}^{2}=\sum_{i=1}^{i=n}\left(B_{0} x_{i}^{\prime 2}+C_{0} y_{i}^{\prime^{2}}+D_{0} z_{i}^{\prime 2}+\right.$ $\left.E_{0} x_{i}^{\prime} y_{i}^{\prime}+F_{0} x_{i}^{\prime} z_{i}^{\prime}+G_{0} y_{i}^{\prime} z_{i}^{\prime}+H_{0} x_{i}^{\prime}+I_{0} y_{i}^{\prime}+J_{0} z_{i}^{\prime}+1\right)^{2}$.

In order to solve Eq. (1), we solve the corresponding Gauss normal equations. Thus, we obtain: $B_{0}=-0.0033, C_{0}=-0.0028$, $D_{0}=-0.0012, E_{0}=0.0008, E_{0}=0.0008, G_{0}=-0.0027, H_{0}$ $=0.1091, I_{0}=0.0531, J_{0}=0.0378$. After making the classical algebraic calculations for quadratic surface classification, we find that surface is an ellipsoid.

Next, we calculate the orthonormal reference system $R=\left\{\theta ; \vec{e}_{1}, \vec{e}_{2}, \vec{e}_{3}\right\}$, where is the center of the ellipsoid $\Gamma$ and $\left\{\vec{e}_{1}, \vec{e}_{2}, \vec{e}_{3}\right\}$ are three orthonormal direction vectors for the three axes of $\Gamma$, such that $\vec{e}_{3}$ is pointed vertically up to the dome. The points in reference system $R$ have coordinates 


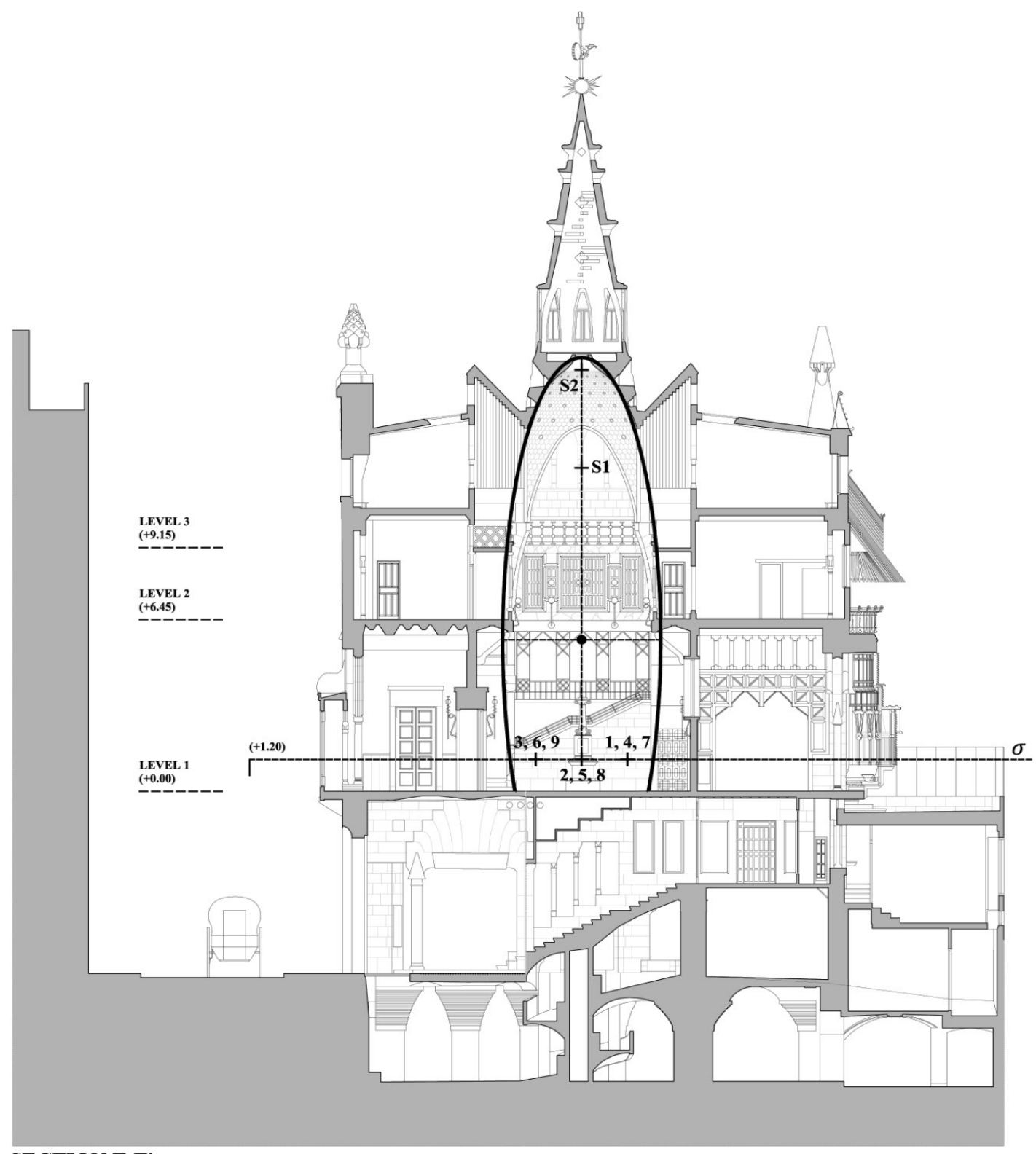

SECTION T-T'

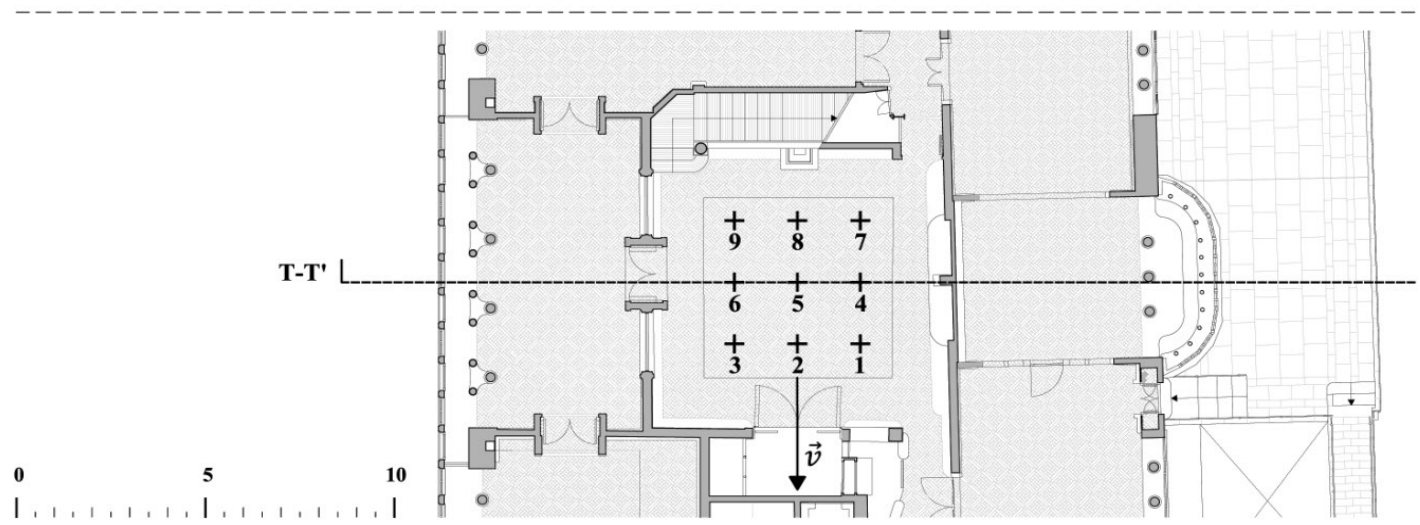

\section{FLOORPLAN LEVEL 1}

Figure 2. Cross-section and plan view for Level 1 of the Central Hall in Palau Güell, showing the positions S1, S2 and an ellipse. S1 marks the position of the organ in Level 3, on the opposite wall from that drawn in section T-T'. S2 marks the position of one focal point of the ellipse, resulting from the intersection between a central vertical plane and the best-fitting quadric surface. This ellipse is outlined with a thick black line. Besides, both in the cross-section and in the plan view, we outline plane or listening plane, where nine receivers are placed (at a height of $1.20 \mathrm{~m}$ above Level 1). Vector shows the listening plane orientation detailed in Figs. 5 and 6 . This graphic document is reproduced with kind permission of the Arxiu del Servei de Patrimoni Arquitectònic Local de la Diputació de Barcelona 
$(x, y, z)$. For this calculation, we consider that $\left\{\vec{e}_{1}, \vec{e}_{2}, \vec{e}_{3}\right\}$ are eigenvectors of the matrix $A_{00}$, and the coordinates of $\theta$ are obtained as a solution of system

$$
A_{00} \vec{x}^{t}=\left(\frac{H_{0}}{2}, \frac{I_{0}}{2}, \frac{J_{0}}{2}\right)^{t} \text {. }
$$

The coordinates of the points from cloud $N$ are changed from reference system $R^{\prime}$ to reference system $R$. In addition to this change, we carry out a normalization consisting of the following three steps. First, the entire cloud $N$ is translated in the direction of vector $\vec{e}_{3}$ until point $D$, the lowest point of $N$, is in plane $z=0$. Second, we carry out a homothetic transformation of the entire cloud $N$ with center on $\theta$ and homothetic ratio $\rho$ such that the distance between point $D$ and $\theta$ is 1 . Third, we rotate the entire cloud $N$ around the axis of $\vec{e}_{3}$ until the coordinates of point $D$ in the system $R$ are $(1,0,0)$. Thus, we obtain a normalized cloud $N=\left\{P_{i}=\left(x_{i}, y_{i}, z_{i}\right)\right\}_{i=1}^{i=n}$ with $D=(1,0,0)$ in system $R=\left\{\theta ; \vec{e}_{1}, \vec{e}_{2}, \vec{e}_{3}\right\}$, where $\vec{e}_{3}$ is the direction vector for the axis of $N$; the new coordinates for the points of cloud $N$ in system $R$ are $\left(x_{i}, y_{i^{\prime}} z_{i}\right)$. After all the above calculations, we obtain the new general Eq. (2) for $\Gamma$, which is the normalized general equation of in system $R$ :

$$
\Gamma \equiv 0=B_{1} x^{2}+C_{1} y^{2}+D_{1} z^{2}+E_{1} x y+J_{1} z+1 .
$$

The coefficients of Eq. (2) for this ellipsoid $\Gamma$ are as follows: $B_{1}=-0.9456, C_{1}=-0.9362, D_{1}=-0.0759$, $E_{1}=0.0087, J_{1}=-0.3181$.

This Eq. (2) allows us to easily find the coordinates of all the geometric elements involved in this paper.

C) The ellipsoid is modeled with AutoCad based on Eq. (2) of the quadratic surface $\Gamma$.

D) The surface is exported to SketchUp, where it is polygonized and joined to the other part of the model.
The end result is a 3D model of the Central Hall made up by 10,237 polygonal shapes, 4110 of which correspond to the surface of the ellipsoidal dome (Fig. 3).

- Step 3: After importing the 3D model into CATT Acoustic, each and every polygonal shape of the model is assigned the properties of its constituent material - texture, porosity, and finish — as well as an absorption parameter and a scattering coefficient.

- Step 4: In the acoustic simulations, the emission source and the sound receivers are positioned according to the abovementioned cases.

4.a. Case 1: An omnidirectional emission source is placed at the organ's location (position S1 in Fig. 2). Nine sound receivers are evenly distributed in a grid layout on plane $\sigma$ parallel to the room's floor at a height of $1.20 \mathrm{~m}$.

4.b. Case 2: An omnidirectional emission source is placed at the upper focal point of the ellipse, resulting from the intersection between a central vertical plane and the ellipsoid $\Gamma$, which best fits the dome (position S2 in Fig. 2). Exactly as for Case 1, nine sound receivers are evenly distributed in a grid layout on plane $\sigma$ parallel to the room's floor at a height of $1.20 \mathrm{~m}$.

- Step 5: Finally we make the corresponding calculations (with CATT Acoustic) in order to find out the main acoustic parameters for both cases. All parameters obtained are averaged values according to ISO $3380-1: 2009$, for frequencies from $125 \mathrm{~Hz}$ to $8 \mathrm{kHz}$.

\section{ACOUSTIC MEASUREMENTS}

As already stated, in order to validate the simulated acoustic values, we collected experimental data onsite. We were only able to collect these experimental acoustic data with the emission source at the position S1. In order to place our emission
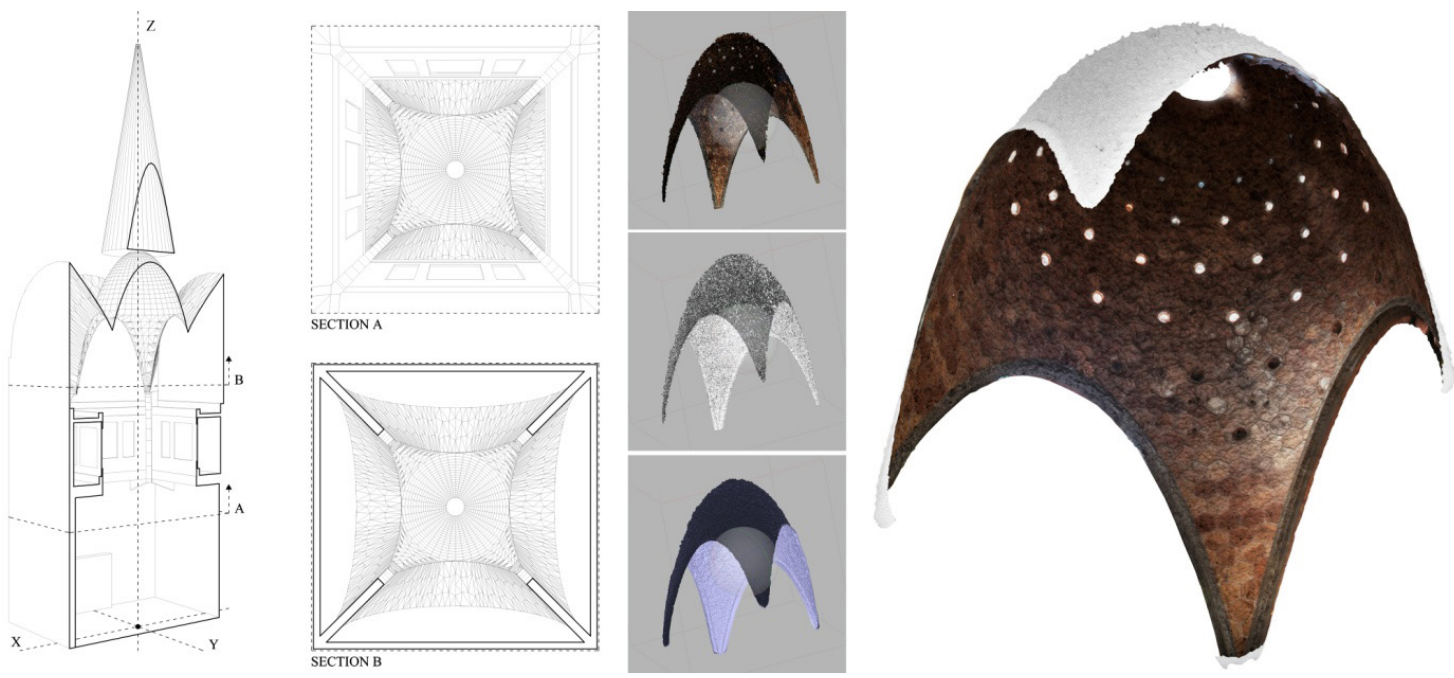

Figure 3. On the right: three-dimensional mesh and textured model based on the point cloud imported into PhotoScan. On the left: three-dimensional model of the Central Hall as imported into CATT Acoustic. This object is generated using SketchUp software, and it is made up by 10,237 polygonal shapes, 4110 of which correspond to the ellipsoidal surface of the dome (image generated by the authors) 
source at the position S2 (the focal point of the ellipsoid), it would have been necessary to put up scaffolding at the Central Hall of Palau Güell. Since this is a very important building in Gaudi's work, we were not authorized to do so. For this reason, we were not able to collect experimental data for our second case, with the emission source at S2.

Experimental data for RIRs were collected in the empty hall and according to ISO 3382-1:2009. The Exponential Sine Sweep (ESS) technique (512 k at $48 \mathrm{kHz}$ ) allowed a proper signal-to-noise ratio ( > $45 \mathrm{~dB}$ ) in each octave band, according to ISO 3382 requirements (ISO 3382-1:2009). One high-SPL dodecahedron and nine monoaural microphones were used simultaneously in order to carry out the whole survey during one day of measurement (D'Orazio et al. 2016). During our measurements, the temperature in the hall ranged between 12 and $14^{\circ} \mathrm{C}$, and the relative humidity ranged between 70 and $75 \%$. The microphone was placed $1.2 \mathrm{~m}$ above the floor level, at the locations marked in Fig. 2.

1. GEOMETRIC CHARACTERISTICS OF THE VIRTUAL MODEL
The acoustic simulation allowed us to assess the acoustic behavior of the hall for one of our cases. The virtual acoustic model was generated from the 3D model described in step 2 above. This 3D model was exported to CATT-Acoustic v.9.0. Table 1 shows the most relevant geometric characteristics of the model used by us.

Table 1. Geometric characteristics of the virtual model

\begin{tabular}{|c|c|}
\hline Floor surface $\left(\mathrm{m}^{2}\right)$ & 66.74 \\
\hline Volume $\left(\mathrm{m}^{3}\right)$ & 1033.88 \\
\hline Total surface $\left(\mathrm{m}^{2}\right)$ & 1228.75 \\
\hline Length/width/height $(\mathrm{m})$ & $8.17 / 8.17 / 25.20$ \\
\hline No. of faces & 10,267 \\
\hline
\end{tabular}

\section{VIRTUAL MODEL CALIBRATION}

The acoustic properties of the surface materials in the 3D model are assigned by means of the parameter values shown in Table 2.

Table 2. Sound absorption coefficients associated to materials in order to calibrate the model ( $\alpha$ : absorption coefficient, s: scattering coefficient).

\begin{tabular}{|c|c|c|c|c|c|c|c|c|}
\hline Material & Surface (\%) & a & $125 \mathrm{~Hz}$ & $250 \mathrm{~Hz}$ & $500 \mathrm{~Hz}$ & $1 \mathrm{kHz}$ & $2 \mathrm{kHz}$ & $4 \mathrm{kHz}$ \\
\hline \multirow{2}{*}{ Stone (Bork, 2005) } & \multirow{2}{*}{46.4} & $\alpha$ & 0.07 & 0.07 & 0.05 & 0.07 & 0.08 & 0.08 \\
\hline & & s & 0.20 & 0.24 & 0.28 & 0.32 & 0.36 & 0.40 \\
\hline \multirow{2}{*}{$\begin{array}{l}\text { Marble or glazed tile (Vorländer, } \\
\text { 2007) }\end{array}$} & \multirow{2}{*}{13.1} & $\alpha$ & 0.01 & 0.01 & 0.01 & 0.02 & 0.02 & 0.02 \\
\hline & & $\mathrm{s}$ & 0.05 & 0.10 & 0.20 & 0.35 & 0.45 & 0.50 \\
\hline \multirow[t]{2}{*}{ Plaster (Vorländer, 2007) } & \multirow{2}{*}{1.6} & $\alpha$ & 0.01 & 0.01 & 0.02 & 0.03 & 0.04 & 0.05 \\
\hline & & s & 0.10 & 0.10 & 0.10 & 0.10 & 0.10 & 0.10 \\
\hline \multirow{2}{*}{ Organ (Alonso et al., 2014) } & \multirow{2}{*}{1.5} & $\alpha$ & 0.12 & 0.14 & 0.16 & 0.16 & 0.16 & 0.16 \\
\hline & & $\mathrm{s}$ & 0.30 & 0.40 & 0.50 & 0.60 & 0.70 & 0.80 \\
\hline \multirow{2}{*}{ Windows (Meyer, 2003) } & \multirow{2}{*}{2.2} & $\alpha$ & 0.35 & 0.25 & 0.18 & 0.12 & 0.07 & 0.04 \\
\hline & & s & 0.01 & 0.01 & 0.05 & 0.10 & 0.20 & 0.25 \\
\hline \multirow{2}{*}{ Solid wooden doors (Bork, 2005) } & \multirow{2}{*}{1.4} & $\alpha$ & 0.14 & 0.10 & 0.06 & 0.08 & 0.10 & 0.10 \\
\hline & & s & 0.30 & 0.40 & 0.50 & 0.60 & 0.70 & 0.80 \\
\hline \multirow{2}{*}{ Wood (Vorländer, 2007) } & \multirow{2}{*}{1.4} & $\alpha$ & 0.10 & 0.15 & 0.18 & 0.20 & 0.20 & 0.20 \\
\hline & & $\mathrm{s}$ & 0.05 & 0.10 & 0.20 & 0.35 & 0.45 & 0.50 \\
\hline
\end{tabular}

\section{VIRTUAL MODEL VALIDATION}

The values obtained for reverberation time (T30) do not exceed 1 JND. A value of 1 JND is an adequate value for parameter $\mathrm{C} 80$ according to Martellota (2010). The values for strength $(G)$ are around 1.5 JND. The values for definition (D50) exceed 2 JND for middle and low frequencies. The values obtained are shown in Fig. 4.

In conclusion, these experimental values allow us to validate the values obtained with the acoustic simulation and analyze the stated cases.

\section{Results}

ANALYTICAL RESULTS

The acoustic model simulations provide the room impulse response (RIR) for each receiver, as well as detailed information on the acoustic characteristics of the Central Hall in Palau Güell. We present the results for spatial impression, perceived 

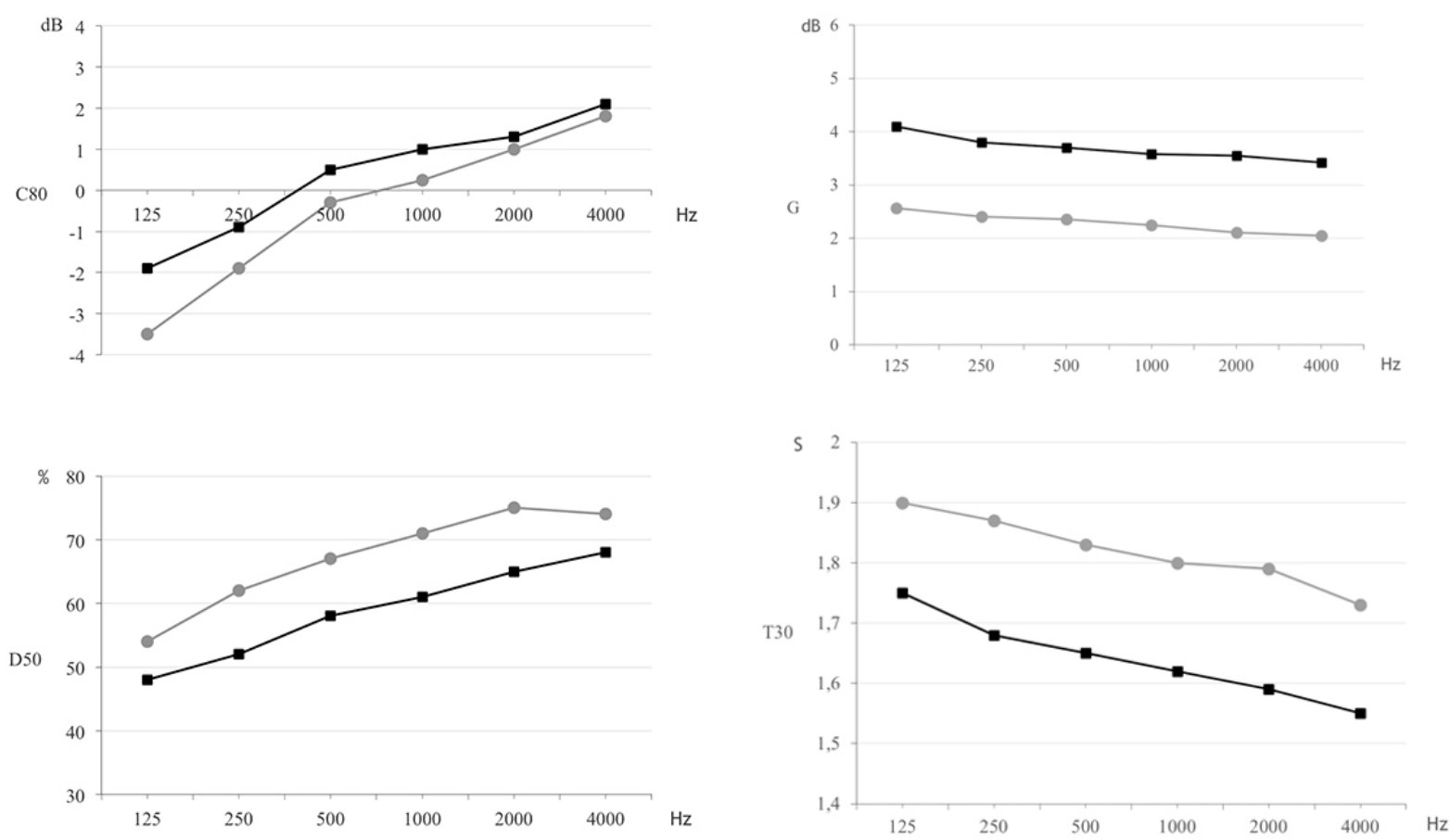

Figure 4. Case 1, comparison of the mean values for parameters C80, G, D50 and T30 as obtained through onsite measurement and through simulation
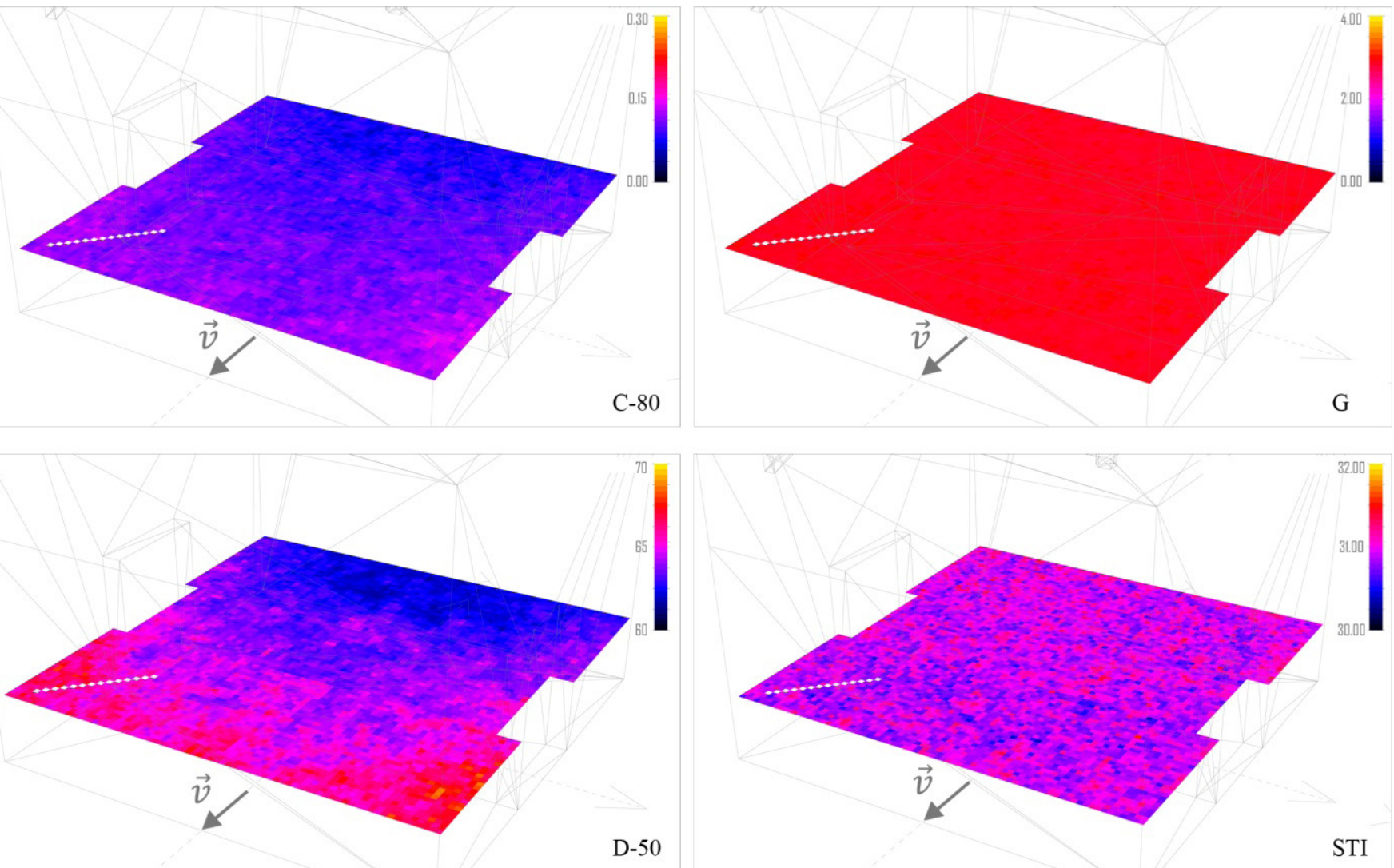

Figure 5. Distribution of the parameters C80, G, D50 and STI for Case 1. Vector determines the orientation of plane $\sigma$ in Fig. 2 
reverberation, and transparency \& intelligibility of speech and music.

With regard to spatial impression, we calculated the value $\mathrm{G}$. With regard to perceived reverberation, we calculated the T30 values. As for the study of transparency and intelligibility of speech and music, we calculated the parameters C80, D50 and STI, as well as the $\mathrm{Br}$ values.

The values obtained for all sound receivers are shown in Table 3 (with a frequency of $1 \mathrm{kHz}$ ) and Table 4. Figs. 5 and 6 show the spatial distribution of several parameter values on plane $\sigma$ (see location in Fig. 2).

Table 3. Average simulation values obtained for both cases

\begin{tabular}{|c|c|c|c|c|c|c|c|c|c|c|c|}
\hline Parameters & Unit & Source & & & & & eceive & & & & \\
\hline \multirow{3}{*}{ G } & \multirow{3}{*}{$\mathrm{dB}$} & & $\mathrm{P} 1$ & P2 & P3 & P4 & P5 & P6 & P7 & P8 & P9 \\
\hline & & S1 & 3.68 & 3.9 & 3.75 & 3.45 & 2.90 & 2.75 & 2.53 & 2.31 & 1.98 \\
\hline & & S2 & 2.45 & 2.56 & 2.41 & 2.35 & 2.25 & 2.11 & 2.05 & 1.85 & 1.55 \\
\hline \multirow[t]{3}{*}{ T30 } & \multirow[t]{3}{*}{$\mathrm{s}$} & $\mathrm{S} 1$ & 1.78 & 1.78 & 1.79 & 1.79 & 1.81 & 1.78 & 1.82 & 1.81 & 1.82 \\
\hline & & S2 & 1.93 & 1.92 & 1.93 & 1.95 & 1.95 & 1.93 & 1.94 & 1.93 & 1.92 \\
\hline & & S2 & 5.43 & 5.44 & 5.43 & 5.43 & 5.40 & 5.44 & 5.40 & 5.45 & 5.43 \\
\hline \multirow[t]{2}{*}{ C80 } & \multirow[t]{2}{*}{$d B$} & S1 & 0.27 & 0.23 & 0.27 & 0.25 & 0.24 & 0.24 & 0.12 & 0.13 & 0.12 \\
\hline & & S2 & -1.92 & -1.94 & -1.94 & -1.94 & -1.37 & -1.95 & -1.94 & -1.95 & -1.93 \\
\hline \multirow[t]{2}{*}{ D50 } & \multirow[t]{2}{*}{$\%$} & S1 & 67.6 & 67.7 & 67.6 & 67.1 & 66.7 & 66.8 & 64.7 & 64.4 & 64.5 \\
\hline & & S2 & 38.2 & 39.5 & 38.8 & 40.3 & 42.6 & 40.7 & 39.6 & 40.6 & 39.1 \\
\hline \multirow[t]{2}{*}{ STI } & \multirow[t]{2}{*}{$\%$} & S1 & 30.9 & 31.4 & 30.7 & 31.5 & 31.1 & 31.1 & 30.1 & 29.8 & 30.2 \\
\hline & & S2 & 33.9 & 33.5 & 33.7 & 34.2 & 44.3 & 34.4 & 33.8 & 33.2 & 33.7 \\
\hline
\end{tabular}

Table 4. Average simulation values obtained for both cases

\begin{tabular}{|c|c|cccccccccc|}
\hline Parameters & Source & \multicolumn{8}{|c|}{ Receivers } \\
\hline \multirow{3}{*}{$\mathrm{Br}$} & \multirow{3}{*}{$\mathrm{S} 1$} & $\mathrm{P} 1$ & $\mathrm{P} 2$ & $\mathrm{P} 3$ & $\mathrm{P} 4$ & $\mathrm{P} 5$ & $\mathrm{P} 6$ & $\mathrm{P} 7$ & $\mathrm{P} 8$ & P9 \\
\cline { 3 - 11 } & $\mathrm{S}$ & 0.94 & 0.95 & 0.93 & 0.93 & 0.92 & 0.94 & 0.95 & 0.95 & 0.94 \\
& $\mathrm{~S} 2$ & 0.93 & 0.95 & 0.92 & 0.93 & 0.92 & 0.95 & 0.95 & 0.95 & 0.95 \\
\hline
\end{tabular}

\section{SIMULATION RESULTS}

After presenting the analytical results of the simulation (Figs. 5, 6 and Tables 3,4 ), we shall now show the impact of each case on the Central Hall acoustics on the basis of: spatial impression, perceived reverberation, and intelligibility of speech and music.

The obtained values are compared to the recommended values. Scientific literature has consolidated several objective acoustic parameters, which characterize the sound environment of an architectural space. Even though these scientific papers usually refer to concert halls and theaters, they can be extrapolated to this hall in view of its intended use (Ando, 1983, 1985; Barron, 1993; Beranek 1996, 2004).

First case: Emission source at position S1 (organ's location)

Fig. 5 shows the distribution of several parameter values in the hall when the emission source is placed at the organ's location (S1). For the parameters C80 and D50, this distribution is dependent on the position of the emission source. Conversely, the distribution of the $G$ values is uniform across the entire listening plane for all frequencies.

The sound strength $(G)$ values in the empty hall lie in the range of 2 to $4 \mathrm{~dB}$ (for the frequency interval between $125 \mathrm{~Hz}$ and $4 \mathrm{kHz}$ ). These values would be good for a concert hall, according to Beranek (1996).

The reverberation time T30, with values close to $1.78 \mathrm{~s}$, is considered acceptable for theater and chorus recitals, according to Beranek (1996). Conversely, Meyer (1993) considers that the appropriate values for organ music are those between 2.5 and $3.0 \mathrm{~s}$.

The music clarity in the room is good, with the $\mathrm{C} 80$ values in the range $-2 \mathrm{~dB}>\mathrm{C} 80>2 \mathrm{~dB}$. The sound is optimal for a concert hall, according to Barron (1993) and Marshall (1994).

The obtained values for the parameter D50 at places near the emission source position S1 are good for opera halls and theaters according to Arau (1999). The clarity of speech decreases at the corners opposite to the emission source. 

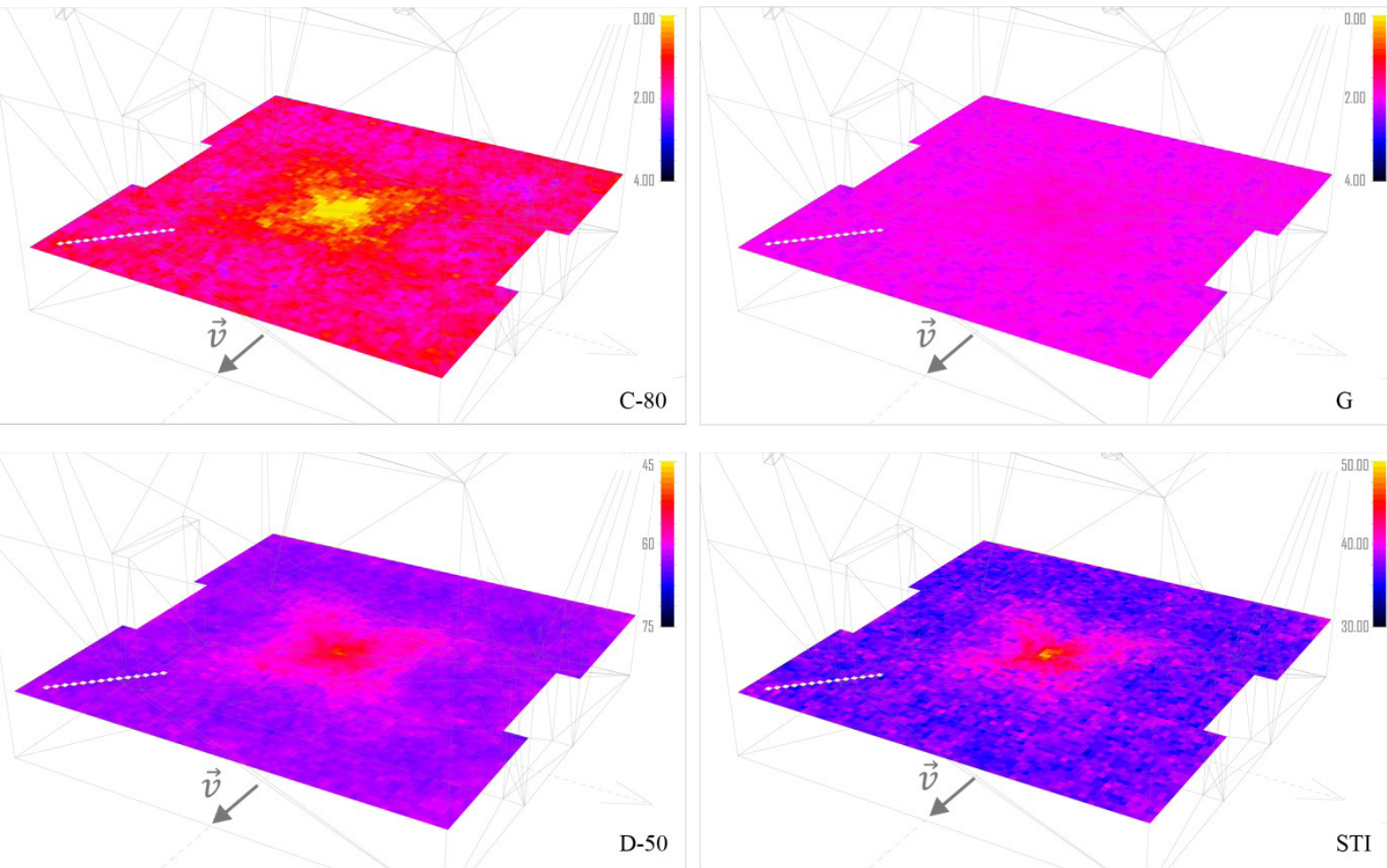

Figure 6. Distribution of the parameters C80, G, D50 and STI for Case 2. Vector $\vec{v}$ determines the orientation of plane $\sigma$ in Fig. 2
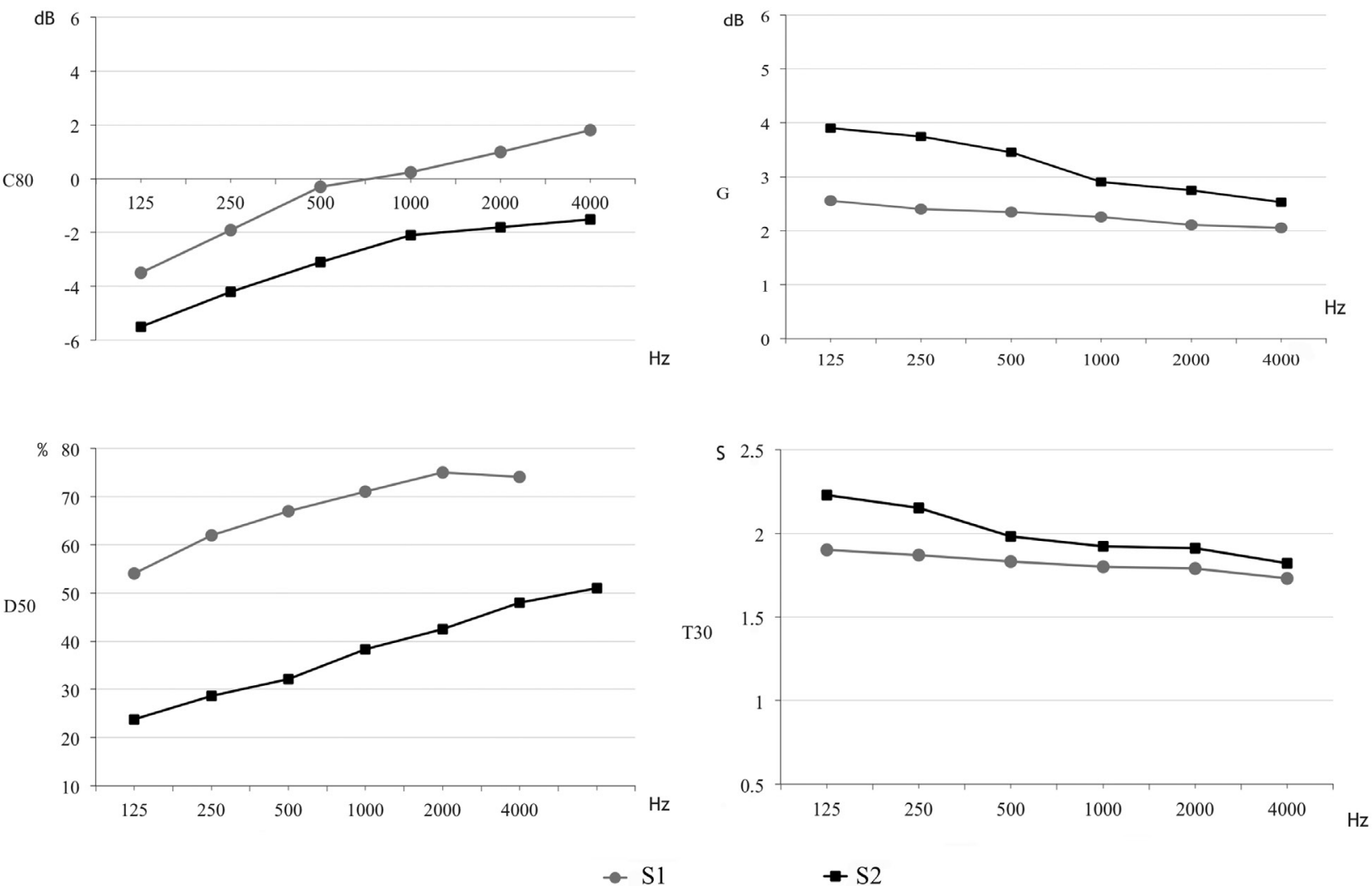

Figure 7. Comparison of the mean values for the parameters C80, G, D50 and T30, as obtained through simulation with the emission source at the organ's location, position S1 (Case 1), and through simulation with the emission source at the focal point of the ellipsoid, position S2 (Case 2) 
The values for speech intelligibility (STI) are considered to be fair according to Arau (1999). The obtained values are not regularly distributed.

We calculated the high-frequency response value $(\mathrm{Br})$, which is close to 1 , suitable for concert halls and theaters. This is a bright room, and the sound is clear and rich in harmonics according to Arau (1999).

The mean value for low-frequency richness (BR) is 0.94 . This value is far from satisfying the strict criterion of warmth for rooms devoted to music. Nonetheless, it is an adequate value for a room that hosts theater plays and dissertations, according to Arau (1999).

Second case: Emission source at position S2 (the focal point of the ellipsoid)

The sound strength of the hall reaches $G$ values of up to $2 \mathrm{~dB}$ (for the frequency interval between 125 $\mathrm{Hz}$ and $4 \mathrm{kHz}$ ), which are good for a concert hall, according to Beranek (1996). As with the first case, the distribution of the $G$ values is almost constant across the entire listening plane.

However, the rest of the parameters are affected by the position of the emission source (S2 in this case). The values obtained for the second case differ strongly from those obtained for the first case. The calculated T30 values are optimal for a room that hosts organ and choral recitals, according to Beranek (1996) (Fig. 6).

The calculated music clarity values (C80) lie in the range from -5 to $0 \mathrm{~dB}$. These are the recommended values for listening to symphonic music, according to Beranek (1996). With high frequencies (higher than $1 \mathrm{kHz}$ ), the values lie within the range recommended by Barron (1993) and Marshall (1994). According to Arau (1999), the definition values (D50) obtained are good for concert and opera halls. The STI values are medium-high (Arau, 1999).
The calculated high-frequency response value $(\mathrm{Br})$ is close to 1 , which indicates again that the sound is rich in harmonics. The BR values obtained for Case 2 are below 1. This is not optimal for a hall that hosts music recitals, but it is good enough for conference rooms or theater halls according to Arau (1999) (Table 5).

\section{Discussion}

In the light of the results shown in the previous section, we note the following considerations:

As far as the parameter $G$ is concerned, the subjective spatial impression of the room is good in both cases. The values obtained are similar for both cases. The spatial distribution of these values is almost constant for both cases.

The T30 values for both cases suggest that the hall is especially suited for listening to choral recitals and also for theater plays. These were the most commonly used musical forms in the Central Hall in Palau Güell. Despite their low sound absorption and high sound scattering properties, the construction materials used in the hall do not affect the T30 values.

The music clarity values (C80) are good in both cases, which means that the hall is well suited to accommodate concerts. However, the distribution of these values on the listening plane is affected by the position of the emission source. Specifically, the spatial distribution resulting from placing the emission source at the organ's location (position S1) fits better with the original use as a concert hall, where the audience was facing the performer (Fig. 5).

The definition values (D50) are good in both cases. Nonetheless, the hall shows a better response for concerts when the emission source is placed in position S1. The distribution of D50 on the listening

Table 5. Reference values for various parameters

\begin{tabular}{|c|c|c|c|c|}
\hline Parameter & Unit & Author & Use of hall & Reference values \\
\hline G & $\mathrm{dB}$ & Beranek & Concert hall & $2.00-6.00$ \\
\hline T30 & $\mathrm{s}$ & $\begin{array}{c}\text { Beranek } \\
\text { Meyer and Newman }\end{array}$ & $\begin{array}{c}\text { Theater } \\
\text { Organ music }\end{array}$ & $\begin{array}{l}0.70-1.20 \\
2.50-3.00\end{array}$ \\
\hline $\mathrm{C} 80$ & $d B$ & $\begin{array}{c}\text { Beranek } \\
\text { Barron and Marshall } \\
\text { Arau }\end{array}$ & $\begin{array}{l}\text { Concert hall } \\
\text { Concert hall } \\
\text { Concert hall } \\
\text { Theater }\end{array}$ & $\begin{array}{c}\mathrm{C} 80<-4.0 / \mathrm{C} 80>0.00 \\
\mathrm{C} 80<-2.0 / \mathrm{C} 80>2.00 \\
\mathrm{C} 80<4.0 / \mathrm{C} 80>0.00 \\
\mathrm{C} 80<6\end{array}$ \\
\hline D50 & $\%$ & Arau & $\begin{array}{l}\text { Theater } \\
\text { Concert hall }\end{array}$ & $\begin{array}{c}\mathrm{D} 50>60 \\
50<\mathrm{D} 50<65\end{array}$ \\
\hline STI & $\%$ & Arau & Concert hall & $\begin{array}{c}0.45-0.60 \text { (acceptable) } \\
0.60-0.75 \text { (good) } \\
0.75-1 \text { (excellent) }\end{array}$ \\
\hline $\mathrm{Br}$ & & Arau & Concert hall & $0.80-1.00$ \\
\hline
\end{tabular}


plane is affected by the position of the emission source. As was the case with the parameter C80, the distribution resulting from placing the emission source at the organ's location (position S1) fits better with the original use of the hall (Fig. 5).

The high-frequency response value $(\mathrm{Br})$ is close to 1 in both cases. This translates into a bright room where the sound is clear and rich in harmonics, which is excellent for listening to sound nuances in music.

The BR values obtained for Case 2 are similar to those obtained for Case 1. These values are not correct for a room that hosts music recitals, but they are adequate for a hall where speech plays a central role.

\section{Conclusions}

Despite the interior finishes and the proportions of space, it is commonly claimed that the Central Hall in Palau Güell has good acoustics. Nonetheless, we are not aware of any rigorous study supporting this impression of acoustic comfort. Furthermore, we are not aware of any original document by Antoni Gaudí explaining why he chose an ellipsoidal dome for this hall or whether this was a deliberate choice, knowing that these surfaces - which are well known since ancient times - provide a good sound distribution in indoor spaces.

After carrying out the acoustical simulations for both cases (Case 1, corresponding to Gaudi's original design; and Case 2, placing the emission source in a different position, which is determined by the geometric parameters of the ellipsoidal dome, in an effort to improve the room acoustics), the following conclusions can be drawn:

1. The values obtained for $\mathrm{C} 80, \mathrm{D} 50$ and $\mathrm{G}$ are good in both cases. Taken as a whole, they are very adequate for this particular hall, the purpose of which is listening to organ and choral music.

2. After analyzing the parameters G, D50, C80 and T30 with the emission source at the organ's location (Case 1), we find that the spatial distribution of these values at the listening plane takes the shape of the area where the audience sat during the concerts held at the hall.

3. Owing to the size and proportions of the hall, the reverberant materials used do not excessively hinder the optimal values for listening to music.

4. Contrary to our expectations, despite having analyzed the geometric parameters of the quadratic surface, which best fits the dome, and placing the emission source in a different position, which is geometrically determined by the dome, we have not succeeded in significantly improving some of the acoustic parameters on the listening plane. Accordingly, despite the absence of a historical document supplying proof in this regard, we believe that Gaudí took the acoustical impact into account when designing this hall.

All the acoustical parameters considered by us in reaching the conclusion that this hall is very well suited for accommodating recitals were unknown at the time the building was constructed. Therefore, Gaudí could not possibly have taken them into account when designing this hall. In spite of that, Gaudi's design fulfills, to a very satisfactory degree, all musical requirements that may apply to a hall specially designed for hosting music recitals.

Finally, we conclude that Gaudí designed an acoustically controlled hall by compensating for the use of reverberant materials with a good geometric conception. The characteristics of the hall - very elongated and topped by an ellipsoidal dome provide good acoustics. Besides, Gaudí took advantage of the dome's geometry and positioned the sound source (organ and choir) in such a way that the audience, who were sitting facing the performer, enjoyed the best possible listening experience. 


\section{References}

Alonso, A., Sendra, J.J., Suarez, R. and Zamarreño, T. (2014). Acoustic evaluation of the cathedral of Seville as a concert hall and proposals for improving the acoustic quality perceived by listeners. Journal of Building Performance Simulation, Vol. 7, Issue 5, pp. 360-378. DOI: 10.1080/19401493.2013.848937.

Alonso, A., Suárez, R. and Sendra, J. J. (2017). Virtual reconstruction of indoor acoustics in cathedrals: The case of the Cathedral of Granada. Building Simulation, Vol. 10, Issue 4, pp. 431-446. DOI: 10.1007/s12273-016-0342-z.

Ando, Y. (1983). Calculation of subjective preference at each seat in a concert hall. The Journal of the Acoustical Society of America, Vol. 74, Issue 3, pp. 873-887. DOI: 10.1121/1.389874.

Ando, Y. (1985). Concert hall acoustics. Berlin: Springer, 154 p.

Arau, H. (1999). ABC de la acústica arquitectónica. Barcelona: CEAC, 336 p.

Barron, M. (1993). Auditorium acoustics and architectural design. London: E \& FN Spon, 504 p.

Beranek, L. L. (1996). Concert and opera halls: how they sound. Woodbury, NY: American Institute of Physics, 643 p.

Beranek, L. (2004). Concert halls and opera houses: music, acoustics, and architecture. $2^{\text {nd }}$ edition. New York: Springer, $661 \mathrm{p.}$

Beranek, L. L. (2008). Concert hall acoustics. Journal of the Audio Engineering Society, Vol. 56, No. 7/8, pp. 532-544.

Berardi, U., lannace, G. and Maffei, L. (2016). Virtual reconstruction of the historical acoustics of the Odeon of Pompeii. Journal of Cultural Heritage, Vol. 19, pp. 555-566. DOI: 10.1016/j.culher.2015.12.004.

Bork, I. (2005). Report on the $3^{\text {rd }}$ round robin on room acoustical computer simulation - Part II: Calculations. Acta Acustica United with Acustica, Vol. 91, No. 4, pp. 753-763.

Bradley, J. S., Reich, R. and Norcross, S. G. (1999). A just noticeable difference in C50 for speech. Applied Acoustics, Vol. 58, Issue 2, pp. 99-108. DOI: 10.1016/S0003-682X(98)00075-9.

Carrión, A. (1998). Diseño acústico de espacios arquitectónicos. Barcelona: Edicions UPC, 434 p.

D'Orazio, D., De Cesaris, S., Guidorzi, P., Barbaresi, L., Garai, M. and Magalotti, R. (2016). Room acoustic measurements using a high SPL dodecahedron. In: Proceedings of the 140th Audio Engineering Society Convention, June 4-7, 2016, Paris, France. Paper 9507. [online] Available at: http://www.aes.org/e-lib/browse.cfm?elib=18206 [Date accessed January 29, 2020].

Giménez, A. (1989). Contribution to the study of acoustics in closed rooms. Application to concert halls. PhD. dissertation. Universitat Politécnica de Valencia. Valencia. Spain. pp.43-68.

Giménez, A., Sanchis, A. M., Sabater, A. S., Faus, J. R., Jordá, S. C. and Vanacloy, M. D. J. (2001). Estudio de la evolución de parámetros acústicos que miden la calidad de salas de conciertos. In: Proceedings of the $32^{\text {nd }}$ Congreso Nacional de Acústica "TecniAcustica". Logroño, Spain. pp. 1-5.

González, A., Lacuesta, R. and Baldomà, M. (2013). El Palacio Güell: Una obra maestra de Antoni Gaudí. $2^{\text {nd }}$ edition. Barcelona: Diputació de Barcelona, 317 p.

Granell, E. (2002). El Palau Güell de Antoni Gaudí en Barcelona: 1886-1888. DC PAPERS, revista de crítica y teoría de la arquitectura, No. 7, pp. 48-55.

Kircheri, A. (1673). Phonurgia nova sive conjugium mechanico-physicum artis \& naturae paranympha phonosophia concinnatum. Rudolphum Dreherr. Kempten. Germany. pp.10-189.

Lahuerta, J. (1992). Antonio Gaudi: Arquitectura, ideología y política. Madrid: Electa. pp. 67-117.

León-Rodríguez, A. L. (1998). La acústica de los teatros a través de la historia. In: Actas del Segundo Congreso Nacional de Historia de la Construcción, October 22-24, 1998, A Coruña, Spain, pp. 263-271.

Marshall, L. G. (1994). An acoustics measurement program for evaluating auditoriums based on the early/late sound energy ratio. The Journal of the Acoustical Society of America, Vol. 96, Issue 4, pp. 2251-2261. DOI: 10.1121/1.410097.

Meyer, J. (1993). Sound of the orchestra. Journal of the Audio Engineering Society, Vol. 41, Issue 4, pp. $203-213$.

Meyer, J. (2003). Kirchenakustik. Frankfurt am Main: Verlag Erwin Bochinsky.

Samper, A., González, G. and Herrera, B. (2017). Determination of the geometric shape which best fits an architectural arch within each of the conical curve types and hyperbolic-cosine curve types: the case of Palau Güell by Antoni Gaudí. Journal of Cultural Heritage, Vol. 25, pp. 56-64. DOI: 10.1016/j.culher.2016.11.015.

Segura, J., Giménez, A., Romero, J. and Cerdá, S. A. (2011). A comparison of different techniques for simulating and measuring acoustic parameters in a place of worship: Sant Jaume Basílica in Valencia, Spain. Acta Acustica United with Acustica, Vol. 97, No. 1, pp. 155-170. DOI: 10.3813/AAA.918396.

Sender, M., Planells, A., Perelló, R., Segura, J. and Giménez, A. (2018). Virtual acoustic reconstruction of a lost church: 
application to an Order of Saint Jerome monastery in Alzira, Spain. Journal of Building Performance Simulation, Vol. 11, Issue 3, pp. 369-390. DOI: 10.1080/19401493.2017.1340975.

Suárez, R., Alonso, A. and Sendra, J. J. (2015). Intangible cultural heritage: The sound of the Romanesque Cathedral of Santiago de Compostela. Journal of Cultural Heritage, Vol. 16, Issue 2, pp. 239-243. DOI: 10.1016/j.culher.2014.05.008.

Tronchin, L. and Knight, D. J. (2016). Revisiting historic buildings through the senses visualising aural and obscured aspects of San Vitale, Ravenna. International Journal of Historical Archaeology, Vol. 20, Issue 1, pp. 127-145. DOI: 10.1007/ s10761-015-0325-2.

Vorländer, M. (2007). Auralization: Fundamentals of acoustics, modelling, simulation, algorithms and acoustic virtual reality. Berlin: Springer, $365 \mathrm{p}$.

Vorländer, M., Schröder, D., Pelzer, S. and Wefers, F. (2015). Virtual reality for architectural acoustics. Journal of Building Performance Simulation, Vol. 8, Issue 1, pp. 15-25. DOI: 10.1080/19401493.2014.888594. 